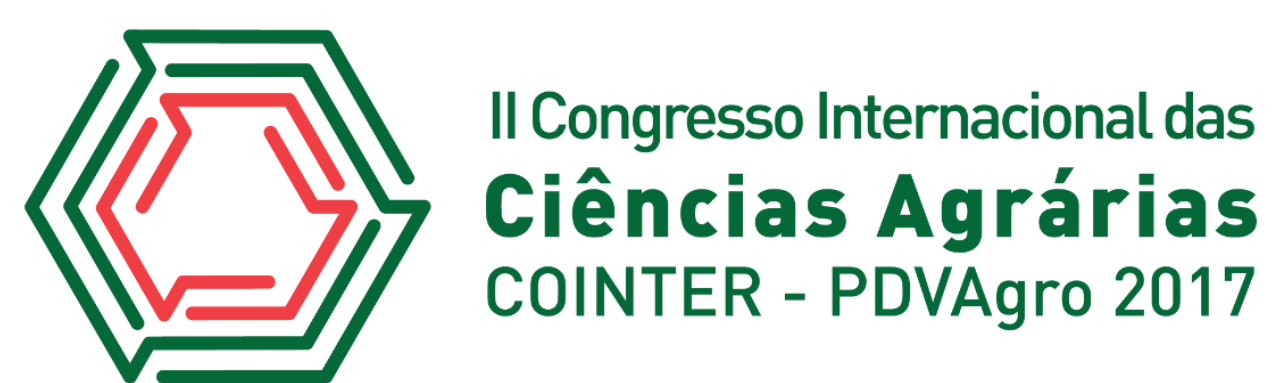

\title{
CONSUMO DE MATÉRIA SECA E DESEMPENHO DE CORDEIROS CONFINADOS ALIMENTADOS COM DIETAS EM DIFERENTES NÍVEIS DE FIBRA EM DETERGENTE NEUTRO
}

\author{
Apresentação: Pôster \\ Pedro Henrique Cavalcante Ribeiro ${ }^{1}$; Migson dos Santos Menezes ${ }^{2}$; Valdi de Lima Júnior³ \\ Stela Antas Urbano ${ }^{4}$; José Hamilton da Costa Filho ${ }^{5}$
}

\section{Introdução}

O consumo alimentar é fator de grande influência na eficiência de um sistema de produção, visto que a ingestão de matéria seca (MS) determina o fornecimento de nutrientes necessários para o atendimento das exigências de mantença e produção dos animais. Essa ingestão alimentar está relacionada com o adequado desempenho produtivo dos ruminantes, que também sofre influência da capacidade adaptativa adquirida por estes em utilizar alimentos fibrosos, com baixa demanda digestiva, como fonte nutricional.

De acordo com Branco et al. (2011), a fibra contém a fração de carboidratos dos alimentos de digestão lenta ou indigerível e impõe limitações sobre o consumo de MS. No entanto, comprovase que o uso da fibra na alimentação de ruminantes é de fundamental importância para manter as atividades de mastigação, motilidade e, consequentemente, a saúde do rúmen, culminando em maior absorção de nutrientes (Alves et al., 2016) e despertando a necessidade de investigar as corretas proporções volumoso:concentrado na dieta desses animais.

Em consciência da importância atribuida à fibra na nutrição de ruminantes, objetivou-se avaliar o consumo de matéria seca e o desempenho de cordeiros alimentados com dietas contendo diferentes níveis de fibras em detergente neutro.

\footnotetext{
${ }^{1}$ Graduando em Zootecnia, UFRN, Natal-RN, Brasil; pedrohcrib@gmail.com

${ }^{2}$ Graduando em Zootecnia, UFRN, Natal-RN, Brasil; migsonmenezes@gmail.com

${ }^{3}$ Professor Adjunto, UFRN, Natal-RN, Brasil; valdi.lima.jr@gmail.com

${ }^{4}$ Professor do programa de Pós-graduação em Produção Animal, PPGPA/UFRN, Brasil; stela_antas@yahoo.com.br

${ }^{5}$ Professor Adjunto, UFRN, Natal-RN, Brasil; hamilton_costa@yahoo.com.br
} 


\section{Fundamentação Teórica}

A fibra é um elemento nutricional caracterizado por apresentar lenta taxa de degradação no rúmen, ou mesmo, indigestibilidade. Os componentes químicos da fibra fazem parte da parede celular das plantas, dispendendo maior tempo necessário para a redução do tamanho dessas estruturas, que depente do conjunto entre a ação física da mastigação e dinâmica da fermentação ruminal (Branco et al., 2011). Assim, segundo Rodrigues et al. (2004), a fibra apresenta, na maioria das vezes, reduzida taxa de trânsito e aumenta a quantidade de resíduos não digeridos que permanecem no rúmen, levando ao efeito de repleção, causador da regulação de consumo de MS.

Para ruminantes, o termo FDN representa a porção da fibra do alimento que é insolúvel em detergente neutro - leia-se celulose, hemicelulose e lignina - sendo então relacionada á regulação de ingestão de alimentos, taxa de passagem e atividade mastigatória desses animais e apresentando, portanto, interferência na qualidade da dieta. A alta concentração de fibra confere, necessariamente, baixa densidade energética à dieta e limita a ingestão por fatores de repleção ruminal, reduzindo a performance animal. Por outro lado, a baixa ingestão de MS pode ser, também, ocasionada pela baixa concetração de fibra, uma vez que as exigências energéticas são supridas em níveis mais baixos de ingestão (Cardoso et al., 2006). Além disso, de acordo com Kozloski et al. (2006), o processo fermentativo ruminal é altamente dependente do $\mathrm{pH}$ do meio, que está diretamente relacionado com o teor de fibra na dieta, que em mínimas quantidades pode comprometer a saúde animal por aumentar a incidência de acidose ruminal. Assim, essas relaçãos tornam a FDN base para formulação de dietas eficientes para ruminantes (Branco et al., 2011).

\section{Metodologia}

O experimento foi conduzido no Setor de Pesquisa em Ovinocultura da Unidade Acadêmica Especializada nas Ciências Agrárias (UAECA) da Universidade Federal do Rio Grande do Norte UFRN, localizada em Macaíba - RN. Foram utilizados 24 cordeiros do genótipo Dorper, não castrados, com peso vivo inicial médio de $16,8 \pm 3,53 \mathrm{~kg}$, desmamados e confinados no segundo mês de vida durante um período experimental de 70 dias.

Os animais foram aleatoriamente distribuídos em quatro tratamentos e alocados em baias individuais de $1 \mathrm{~m}^{2}$, equipadas com comedouro e bebedouro. As dietas experimentais foram isoproteicas (15\% de proteína bruta) e compostas por concentrado e feno de tifton 85 (Cynodon dactylon), diferindo entre si quanto ao teor de fibras em detergente neutro (21, 30, 39 e 48\%) 
(Tabela 1). O arraçoamento foi realizado uma vez ao dia (07h), na forma de mistura total, com oferta da ração ad libitum. As sobras foram pesadas diariamente, possibilitando o cálculo do consumo e o ajuste da oferta de modo a permitir sobras de $10 \%$.

Tabela 1- Proporções dos ingredienes (\%MS) utilizados nas formulações das dietas experimentais. Fonte: Própria

Itens $(\%)$

Nível de FDN

Level of NDF

\begin{tabular}{lcccc}
\hline & $21 \%$ & $30 \%$ & $39 \%$ & $48 \%$ \\
\cline { 2 - 5 } Soja, farelo (min 46\% PB) & 17,00 & 16,00 & 16,00 & 16,00 \\
Milho, grão moído & 66,00 & 53,00 & 39,00 & 25,00 \\
Feno de Tifton & 13,00 & 27,00 & 41,00 & 55,00 \\
Sal mineral & 4,00 & 4,00 & 4,00 & 4,00 \\
\hline
\end{tabular}

Os animais foram pesados, em jejum, no início do experimento e a cada sete dias para melhor acompanhamento do desempenho animal. Com base dessa informação, determinou-se semanalmente, a cada nova pesagem, o ganho médio diário (GMD) pelo cálculo do ganho em relação à pesagem anterior dividido para os 7 dias de intervalo. Realizou-se ainda uma última pesagem ao final do experimento para determinar o ganho de peso total (GT) pela diferença do peso ao início e ao fim do confinamento.

O delineamento experimental foi inteiramente casualizado, com quatro tratamentos e seis repetições, sendo a unidade experimento representada pelo animal. Os dados foram tabulados em planilhas eletrônicas e submetidos à análise de variância e regressão, considerando o nível de 5\% de probabilidade para o erro do tipo I, para avaliar o consumo e o ganho de peso animal em função do nível de fibra em detergente neutro da dieta.

\section{Resultados e Discussões}

O aumento da concentração de fibras nas dietas experimentais apresentou significância para todas as variáveis (tabela 2 ).

Tabela 2 - Médias, coeficiente de variação e equações de regressão do consumo de matéria seca (CMS), ganho de peso diário (GMD), ganho de peso total (GT) e peso ao final do experimento (PF) de cordeiros alimentados com dietas em diferentes níveis de fibra em detergente neutro (FDN). Fonte: Própria

\section{Nível de FDN (\%)}

Variável Level of $\mathrm{NDF}$

P 


\begin{tabular}{|c|c|c|c|c|c|c|c|c|}
\hline $21 \%$ & $30 \%$ & $39 \%$ & $48 \%$ & $\begin{array}{l}\text { CV } \\
(\%)\end{array}$ & $\mathbf{L}$ & $\mathbf{Q}$ & ER & $\mathbf{r}^{2}$ \\
\hline 0,91 & 1,04 & 0,96 & 0,7 & 19,54 & 0,04221 & 0,01299 & $\begin{array}{l}\hat{Y}=-0,0012 x^{2}+ \\
0,075 x+0,1342\end{array}$ & 0,37 \\
\hline 0,22 & 0,22 & 0,17 & 0,09 & 24,57 & 0,00002 & 0,0361 & $\begin{array}{l}\hat{Y}=-0,0002 x^{2}+ \\
0,0121 x+0,0801\end{array}$ & 0,65 \\
\hline 16,36 & 16,26 & 12,6 & 6,63 & 24,5 & 0,00002 & 0,03502 & $\begin{array}{l}\hat{Y}=-0,0181 x^{2}+ \\
0,8842 x+5,847\end{array}$ & 0,65 \\
\hline 33,13 & 33,23 & 29,4 & 23,6 & 19,48 & 0,00624 & 0,22823 & $\begin{array}{c}\hat{Y}=-3,242 x+ \\
37,945\end{array}$ & 0,86 \\
\hline
\end{tabular}

Houve efeito quadrático para o consumo de matéria seca, com valor máximo de 1,04 kg quando o nível de FDN foi de 30\%. De forma geral, as médias foram maiores que os reportados por Cardoso et al., (2006), que ao trabalharem com níveis de fibras próximos aos estudados neste trabalho para cordeiros provenientes do cruzamento entre Ile de France e Texel, encontraram valores decrescentes $(0,968 ; 0,959 ; 0,773$ e $0,765 \mathrm{~kg} / \mathrm{animal} / \mathrm{dia})$ com o aumento de FDN na dieta $(25 \%, 31 \%, 37 \%$ e $43 \%)$ respectivamente. De acordo com Van Soest et al., (1994), o consumo sofre relação inversa ao teor de FDN dos alimentos.

O aumento do teor de fibras na dieta dos cordeiros promoveu um comportamento quadrático no ganho de peso médio diário dos animais, sendo observado ganho máximo de 0,263 kg, quando o nível de FDN foi de 30\%. O maior GMD dos cordeiros com os menores teores de FDN é explicado pela maior quantidade de concentrado e, em decorrência disto, maior teor de energia destas dietas (Cardoso et al., 2006). Para o ganho de peso total também houve efeito quadrático, com máximo de $16,64 \mathrm{~kg}$ para $21 \%$ de FDN. Já o peso final, que reflete o consumo e desempenho ao longo do período experimental, decresceu linearmente de acordo com o incremento dos teores de fibra na dieta.

O fornecimento de maiores quantidades de concentrado permite aumentar a concentração de nutrientes nas dietas (Moreno et al., 2010) possibilitando melhor aporte nutricional e desempenho animal como o encontrado para as dietas com 21 e 30\% de FDN. No entanto, ocasionam também, a elevação dos custos de produção e aumentam o risco de ocorrência de distúrbios metabólicos tornando o nível de 30\% mais recomendado. Este resultado corrobora com Cardoso et al. (2006) e Branco et al. (2011), que recomendaram os níveis de $31 \%$ e $28 \%$ de FDN, respectivamente, na nutrição de pequenos ruminantes. 


\section{Conclusões}

O aumento dos teores de fibra na alimentação de ovinos de corte pode reduzir o desempenho e a produção desses animais. Dentre os níveis estudados, recomenda-se a utilização do nivel de $30 \%$ de FDN por propiciar maior consumo de matéria seca e ganho médio diário.

\section{Referências}

AlveS, A. R.; PASCOAL, L. A. F.; CAMBUí, G. B.; Silva TRAJANO, J.; SILVA, C. M. \& GOIS, G. C. Fibra para ruminantes: Aspecto nutricional, metodológico e funcional. PUBVET, v. 10, p. 513-579, 2016.

BRANCO, R. H., RODRIGUES, M. T., SILVA, M. M. C., RODRIGUES, C. A., QUEIROZ, A. C., e ARAUJO, F. L. Desempenho de cabras em lactação alimentadas com dietas com diferentes níveis de fibra oriundas de forragem com maturidade avançada. Revista Brasileira de Zootecnia, v. 40, n. 5, p. 1061-1071, 2011.

CARDOSO, A.R.; PIRES, C.C.; CARVALHO, S. GALVANI, D.B.; JOCHIMS, F.; HASTENPFlUG, M.; WOMMER, T. P. Consumo de nutrientes e desempenho de cordeiros alimentados com dietas que contêm diferentes níveis de fibra em detergente neutro. Ciência Rural, v.36, n.1, p.215-221, 2006.

KOZlOSKI, G. V., TREVISAN, L. M., BONNECARRERE, L. M., HARTER, C. J., FIORENTINI, G., GALVANI, D. B., e PIRES, C. C. Níveis de fibra em detergente neutro na dieta de cordeiros: consumo, digestibilidade e fermentação ruminal. Arq. bras. med. vet. zootec, v. 58, p. 893-900, 2006.

MORENO, G. M. B., SOBRINHO, S., GARCIADA, A., LEÃO, A. G., LOUREIRO, C. M. B., PEREZ, H. L., e ROSSI, R. C. Desempenho, digestibilidade e balanço de nitrogênio em cordeiros alimentados com silagem de milho ou cana-de-açúcar e dois níveis de concentrado. Revista Brasileira de Zootecnia, p. 853-860, 2010.

RODRIGUES, M.T. Alimentação de cabras leiteiras. In: ENDEC - ENCONTRO NACIONAL PARA O DESENVOLVIMENTO DA ESPÉCIE CAPRINA, 8., 2004, Botucatu. Anais... Botucatu, 2004. p.121-154.

VAN SOEST, P. J. Nutritional Ecology of the Ruminant. 2.ed. New York: Cornell University Press, 1994. $476 \mathrm{p}$. 